\title{
In the eyes of older adults: Self-reported age and adjustment in African and European older adults
}

\begin{abstract}
Authors:
Sofia von Humboldt ${ }^{1}$

Isabel Leal ${ }^{1}$

Filipa Pimenta ${ }^{1}$

Georgeta Niculescu ${ }^{2}$

\section{Affiliations:}

${ }^{1}$ Research Unit in Psychology and Health, ISPA-Instituto,

Universitário Lisbon, Portugal

${ }^{2}$ Romanian Association

of Person-Centered

Psychotherapy, Romania

Correspondence to:

Sofia von Humboldt

Email:

sofia.humboldt@gmail.com
\end{abstract}

\section{Postal address:}

Rua Jardim do Tabaco, N 34

1149-041 Lisbon

Dates:

Received: 31 Oct. 2012

Accepted: 03 June 2013

Published: 09 Sept. 2013

How to cite this article:

Von Humboldt, S., Leal, I.

Pimenta, F. \& Niculescu, G.,

2013, 'In the eyes of older

adults: Self-reported age

and adjustment in African

and European older adults',

Health SA Gesondheid 18(1),

Art. \#712, 10 pages.

http://dx.doi.org/10.4102/

hsag.v18i1.712

\section{Copyright:}

(C) 2013. The Authors.

Licensee: AOSIS

OpenJournals. This work

is licensed under the

Creative Commons

Attribution License.
Read online:
To explore older adults' perceptions of subjective age and adjustment to ageing and to analyse the correlational structure of the pre-categories in our study: subjective age, indicators of adjustment to ageing and of personal age perception. An exploratory, descriptive mixedmethods design was utilised. A purposive sampling method was used to select 154 older adults aged between 75 and 99 years from three different nationalities. Semi-structured interviews were performed, addressing two core areas: subjective age and adjustment to ageing. Data was subjected to content analysis. Representation of the correlational structure of the precategories in our study (subjective age and indicators of adjustment to ageing) were analysed by a Multiple Correspondence Analysis. Standardised instruments measured regular cognitive abilities. Five categories derived from interviews for subjective age: 'adapted', 'disconnected', 'old', 'youthful' and 'tolerant'. A total of seven categories emerged as indicators of adjustment to ageing: 'social networking', 'health', 'time perspective', 'spirituality', 'financial autonomy', 'professional activities' and 'fulfilment and leisure'. These results supported a model for each pre-category. Subjective age was explained by a two-factor model: 'age-conscientious' and 'youthful'. A three-dimensional model formed by 'reconciled', 'satisficers' and 'maximisers' was indicated as a best-fit solution for adjustment to ageing. A three-dimensional overall model for PAP was formed by 'age-cognisant', 'fulfilled' and 'satisficers'. The findings highlighted the underdeveloped potential of subjective age, adjustment to ageing and a personal age perception overall model for this population. Enhancing subjective age and adjustment to ageing might be an important target to improve older adults' interventions' outcomes.

Hierdie artikel het ten doel om ouer volwassenes se persepsies aangaande subjektiewe ouderdom en aanpassing by veroudering te ondersoek en om die korrelatiewe struktuur van die pre-kategorieë te ontleed: subjektiewe ouderdom, indikators van aanpassing by veroudering en persepsies oor persoonlike ouderdom. Die artikel gebruik 'n eksploratiewe, deskriptiewe gemengdemetode-ontwerp. ' $n$ Doelgerigte steekproefmetode is gebruik om 154 ouer volwassenes tussen die ouderdom van 75 en 99 uit drie verskillende nasionaliteite te kies. Semi-gestruktureerde onderhoude is met hulle gevoer en dit het op twee kerngebiede gefokus: subjektiewe ouderdom en aanpassing by veroudering. Die data is aan ' $n$ inhoudsanalise onderwerp. Die representasie van die korrelatiewe struktuur van die pre-kategorieë in die studie (subjektiewe ouderdom en indikators van aanpassing by veroudering) is met behulp van ' $n$ veelvuldige-ooreenkoms-analise gedoen. Gestandaardiseerde instrumente het reguliere kognitiewe vermoëns gemeet. Vyf kategorieë vir subjektiewe ouderdom is uit die onderhoude afgelei: 'aangepas', 'gediskonnekteer', 'oud', 'jeugdig' en 'verdraagsaam'. 'n Totaal van sewe kategorieë het as indikators van aanpassing by veroudering na vore gekom: 'sosiale netwerking', 'gesondheid', 'tydsperspektief', 'spiritualiteit', 'finansiële outonomiteit', 'professionele aktiwiteite' en 'vervulling en vrye tyd'. Die resultate ondersteun 'n model vir elke pre-kategorie. Subjektiewe ouderdom is deur ' $n$ tweefaktor-model verduidelik: 'ouderdomsbewustheid' en 'jeugdig'. 'n Driedimensionele model is as die beste oplossing vir aanpassing by verandering aangedui, te wete 'versoen, 'tevrede met wat voldoende is' (satisficers) en 'maksimaliseerder'. 'n Oorkoepelende driedimensionele model vir PAP (die Sielkundevereniging van die Filippyne) is gevorm deur die kategorieë 'ouderdom-bewus', 'vervul' en 'tevrede met wat voldoende is'. Die bevindings beklemtoon die onderontwikkelde potensiaal van subjektiewe ouderdom, aanpassing by veroudering en 'n oorkoepelende model vir persepsies oor persoonlike ouderdom in hierdie populasie. Die bevordering van subjektiewe ouderdom en aanpassing by veroudering sou belangrike doelwitte kon wees ten einde intervensie-uitkomste onder ouer volwassenes te verbeter.

\section{Introduction}

The world is ageing. In fact, the number of people over the age of 60 is projected to reach almost two billion by 2050 , representing $22 \%$ of the world's population. The proportion of individuals aged 80 or over is projected to rise from $1 \%$ to $4 \%$ of the global population between today and 
2050 (United Nations 2009). Because of the undeniable 'graying of society', European and North American countries have been investing strongly in psychological research on the development of health in late life and on interventions that promote the wellbeing of older adults (Fernández-Ballesteros 2007:15). Although data-collection efforts on the status of older Africans have increased in recent years (Charlton 1998; Ferreira et al. 1992), a paucity of quality data concerning this group remains, yet the growth of elderly African populations poses unique policy challenges and information needs concerning older adults (World Health Organization 2003). Moreover, previous literature emphasises the fact that cultural, national and ethnic differences may influence the process of ageing (Barak 2009; Torres 2003) and that ageing is an ongoing process which requires continuous adjustment (Birren \& Schaie 1996). In fact, sociocultural factors play a crucial role in affecting the way in which individuals see themselves as changing in later life (Westerhof, Whitbourne \& Freeman 2011:53).

Despite the fact that chronological age is the basic dimension along which physical and psychological outcomes are investigated amongst older adults, a growing body of research has considered that subjective age (SA) is an interesting personal dimension along which to explore individual functioning (Barak 2009; Montepare 2009; Schafer \& Shippee 2010). Indeed, SA is a multidimensional construct assessing facets such as felt age and perceived age (Kotter-Grühn \& Hess 2012:563; Ward 2010). Moreover, SA derives from a process of anchoring and adjusting personal age perceptions (PAP), considering distal cues (i.e. internal representations of developmental models) and proximal reference points (i.e. historic, physical, normative and interpersonal age markers) that guide the age that individuals across the lifespan perceive themselves to be (Montepare 2009:42). Furthermore, PAP reflects age and ageing as an individual experience. This entails personal age attitudes toward one's own ageing, awareness of age-related change and the perception of SA as including cultural and personal meanings that a person relates to his or her age (Diehl \& Wahl 2010; Schafer \& Shippee 2010).

Considering that the ageing process is multidimensional and multidirectional, perceptions and experiences of one's own ageing process refer to the meaning of different aspects of the ageing process as they relate to one's own person (Westerhof et al. 2011:52). Previous studies suggest that the personal experience of ageing consists of three dimensions: physical decline, social loss and psychological growth (Steverink et al. 2001:365) and that these relate differentially to personal and social resources, including social relations, education and health (Westerhof et al. 2011:53). Furthermore, identity process theory (Whitbourne 1986) proposes that adjustment to ageing (AtA) can be conceptualised as involving the three processes of identity assimilation (maintaining selfconsistency), identity accommodation (making changes in the self) and identity balance (maintaining a sense of self but changing when necessary), whereas according to Brandstädter and Greve's 1994 model, adjustment of a person's goals and aspirations in the face of age-related challenges corresponds to what the authors named 'accommodation'. Although insufficient attention has been paid to AtA in gerontological literature (Kozma, Stones \& McNeil 1991), growing evidence suggests that AtA should be a relevant key consideration in order for research and health practitioners to comprehend the implications of old age and longevity (Slangen-de Kort et al. 2001; Staudinger \& Kunzmann 2005).

AtA and SA are distinct concepts in gerontological literature, yet they are related to the multidimensional and multicultural context of adjustment and age (Barak 2009; Kotter-Grühn \& Hess 2012; Torres 2003). Moreover, their in-depth analysis and possible association can contribute to assessing an overarching view of PAP. This research design is therefore appropriate with regard to uncovering older adults' perspectives concerning the multidimensional context of ageing well.

\section{Problem statement}

The health and well-being of older people has been recognised as being one of the most pressing and universal social issues of our time (Fernández-Ballesteros 2007:15). Although early gerontological research indicated that development in old age was characterised by an increasingly negative gainloss ratio, further studies have shown that a positive ageing experience is related to higher wellbeing and that positive self-perceptions of ageing predict better functioning in later life (Levy 2003:210; Westerhof et al. 2011:53). Although some previous studies have been developed concerning subjective age and ageing, there is still a need for deepening the older adults' perceptions of SA and AtA, as these may become a significant means for healthcare interventions, thereby improving wellbeing and longevity (Fernández-Ballesteros 2007; Staudinger \& Kunzmann 2005). Furthermore, in view of the limited number of studies that relate these two constructs amongst older adults, this research aims to help bridge this gap.

The following research questions were thus asked: (1) How do older adults perceive SA and AtA?; and (2) What is the pattern of relationships of SA, indicators of AtA and of AtA based on the PAP model?

\section{Aims of the study}

This study aims at making a relevant contribution to the existing literature by (a) exploring older adults' SA and indicators of AtA; and (b) analysing the correlational structure of the pre-categories in our study: SA, indicators of AtA and a PAP overall model.

\section{Significance of the study}

The significance of the study is to provide original data on the conceptualisations of a cross-national older population concerning SA and AtA, given the multidimensional and multicultural context of adjustment and age and the relevance of these concepts as becoming a significant means 
for improving wellbeing and longevity in an ageing world. In this way, the study provides an exploratory basis for the deepening of the potential of SA, AtA and PAP in clinical practice and health promotion in older populations.

\section{Research method and design Design}

An exploratory, descriptive mixed-methods design was utilised. Semi-structured interviews were used to explore the different conceptualisations of SA and AtA, as described by non-institutionalised older adults aged 75 and over, living in the community. Representation of the correlational structure of the precategories in our study (SA and indicators of AtA) were analysed by a Multiple Correspondence Analysis (MCA). This research design allowed the researcher to explore the participants' perspectives in order to gain insight into and an understanding of the phenomena in question (Brink 2006:113; Burns \& Grove 2005:52).

Because the study attempted to understand the phenomena from the perspective of the older adults, the research was conducted inductively. Elderly people were studied in their setting in order to uncover the uniqueness of perspectives concerning the multidimensional context of age and adjustment, by talking to them (Holloway \& Wheeler 2002:17). Older adults reported their perceptions and these perceptions were reflected in words and quotations that were used to highlight the diverse aspects that were narrated (Burns \& Grove 2001:61; Polit \& Hungler 2004:50).

\section{Participants and sampling}

The sample for the current study comprised 154 eligible, community-dwelling older adults from three different nationalities (Angolan, Romanian and English). Participants were aged 75 years and over $(\mathrm{M}=83.7$; $\mathrm{SD}=6.249$; range $75-99), 57.8 \%$ women, $50.6 \%$ married and $61.7 \%$ professionally inactive. The recruitment of participants was performed through senior universities' message boards, local and art community centres' list-serves in the Bucharest metropolitan area (in Romania), in the Lisbon metropolitan area and in the Algarve region (in Portugal). Angolan and English participants were recruited in Lisbon and the Algarve and Romanian participants in Bucharest. Sampling was performed purposefully, with the objective of facilitating the understanding of SA and indicators of AtA in a cross-national sample. The three nationality groups are homogeneous demographically, except for the education level, as shown in Table 1.

Interviews of Angolan and English participants were performed in Portuguese, as both nationality groups were fluent in Portuguese and were residents of Lisbon and the Algarve. The Romanian interviews were performed in the Romanian language as this was the primary language of these participants. We proceeded in the classical manner of translation and retroversion. The translation of the interviews was performed by 2 psychologists with linguistic competence certificates. These made independent translations. The final version was then submitted to retroversion by a third person and was compared against the original interview. Participants were included if they had been diagnosed with no concurrent severe mental disorders, according to DSM-IV, if they were willing to share their self-reports of SA and indicators of AtA and if they scored in the normal range on the Mini Mental Status Exam (> 26) (MMSE) (Folstein, Folstein \& McHugh 1975). The MMSE was administered to all participants using standardised procedures. Table 1 shows the characteristics of the study's participants.

\section{Data collection method}

Semi-structured individual interviews based on an interview guide were conducted in the participants' own homes (see Figure 1). A number of participants were living with their children. The participants were provided with a brief description of the study over the phone or in person and were invited to participate in person-to-person interview. The interviews lasted from 25 to 50 minutes. All the participants gave their informed consent after the presentation of the study. Each interview was performed individually and began with a set of straightforward background questions, in order to find out about the participant's living arrangements, health, nationality, age, family, education and work, followed by two open-ended questions that were created in order to

TABLE 1: Distribution of the study's participants according to sociodemographic and health-related characteristics.

\begin{tabular}{|c|c|c|c|c|c|c|c|c|}
\hline \multirow[t]{2}{*}{ Variable } & \multicolumn{2}{|c|}{ Angolan } & \multicolumn{2}{|c|}{ Romanian } & \multicolumn{2}{|c|}{ English } & \multicolumn{2}{|c|}{ Total } \\
\hline & $N$ & $\%$ & $N$ & $\%$ & $n$ & $\%$ & $n$ & $\%$ \\
\hline \multicolumn{9}{|l|}{ Participants } \\
\hline Sample size & 53 & - & 49 & - & 52 & - & 154 & - \\
\hline Age (M; SD) & 83.7 & 6.509 & 83.5 & 6.269 & 84.0 & 6.068 & 83.7 & 6.249 \\
\hline \multicolumn{9}{|l|}{ Gender } \\
\hline Male & 23 & 43.4 & 20 & 40.8 & 22 & 42.3 & 65 & 42.2 \\
\hline Female & 30 & 56.6 & 29 & 59.2 & 30 & 57.7 & 89 & 57.8 \\
\hline \multicolumn{9}{|l|}{ Education } \\
\hline Primary school & 16 & 30.2 & 6 & 12.2 & 4 & 7.7 & 26 & 16.9 \\
\hline Middle school & 23 & 43.4 & 8 & 16.3 & 15 & 28.8 & 46 & 29.9 \\
\hline High school & 9 & 17.0 & 21 & 42.9 & 21 & 40.4 & 51 & 33.1 \\
\hline $\begin{array}{l}\text { University degree or } \\
\text { higher }\end{array}$ & 5 & 9.4 & 14 & 28.6 & 12 & 23.1 & 31 & 20.1 \\
\hline \multicolumn{9}{|l|}{ Marital status } \\
\hline $\begin{array}{l}\text { Married or in a } \\
\text { relationship }\end{array}$ & 24 & 45.3 & 25 & 51.0 & 29 & 55.8 & 78 & 50.6 \\
\hline Single & 12 & 22.6 & 11 & 22.4 & 13 & 25.0 & 36 & 23.4 \\
\hline Widowed & 17 & 32.1 & 13 & 26.6 & 10 & 19.2 & 40 & 26.0 \\
\hline \multicolumn{9}{|l|}{ Professional status } \\
\hline Active & 22 & 41.5 & 17 & 34.7 & 20 & 38.5 & 59 & 38.3 \\
\hline Inactive & 31 & 58.5 & 32 & 65.3 & 32 & 61.5 & 95 & 61.7 \\
\hline \multicolumn{9}{|l|}{ Family annual income } \\
\hline$\leq 10000 €$ & 21 & 39.6 & 13 & 26.5 & 11 & 21.2 & 45 & 29.2 \\
\hline $10001-20000 €$ & 20 & 37.7 & 20 & 40.8 & 20 & 38.5 & 60 & 39.0 \\
\hline $20001-37500 €$ & 7 & 13.2 & 12 & 24.5 & 10 & 19.2 & 29 & 18.8 \\
\hline $37501-70000 €$ & 2 & 3.8 & 2 & 4.1 & 4 & 7.7 & 8 & 5.2 \\
\hline$\geq 70001 €$ & 3 & 5.7 & 2 & 4.1 & 7 & 13.4 & 12 & 7.8 \\
\hline \multicolumn{9}{|l|}{ Perceived health } \\
\hline Good & 27 & 50.9 & 30 & 61.2 & 35 & 67.3 & 95 & 61.7 \\
\hline Poor & 26 & 49.1 & 19 & 38.8 & 17 & 32.7 & 59 & 38.3 \\
\hline
\end{tabular}


be free of bias and to allow any kind of narrative, as well as to facilitate the fluency of the participants' narratives about their perceptions. These questions were: 'How do you feel about your age?' and 'I would like to understand what, in your point of view, contributes to your adjustment to ageing in this phase of your life'. These questions were elaborated on to address the core areas of SA and indicators of AtA. The results from each stage of data collection are presented in Figure 2.

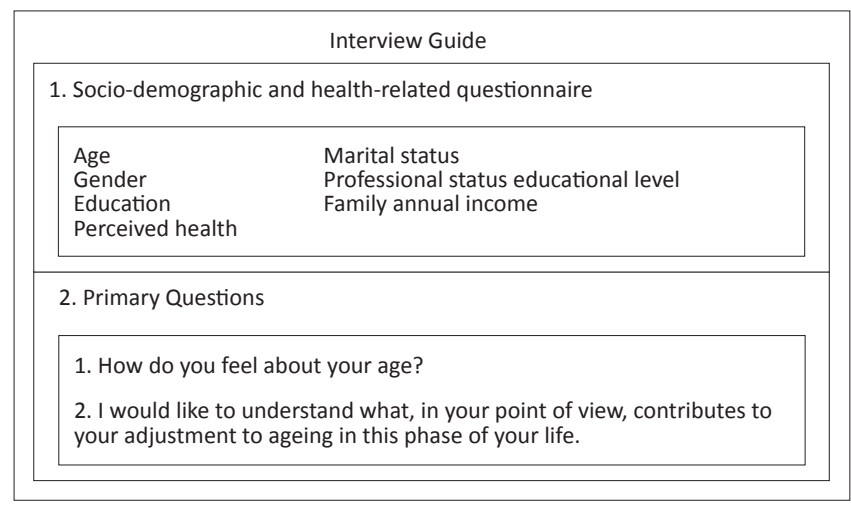

Source: Authors' own construction

FIGURE 1: Data-collection instrument.

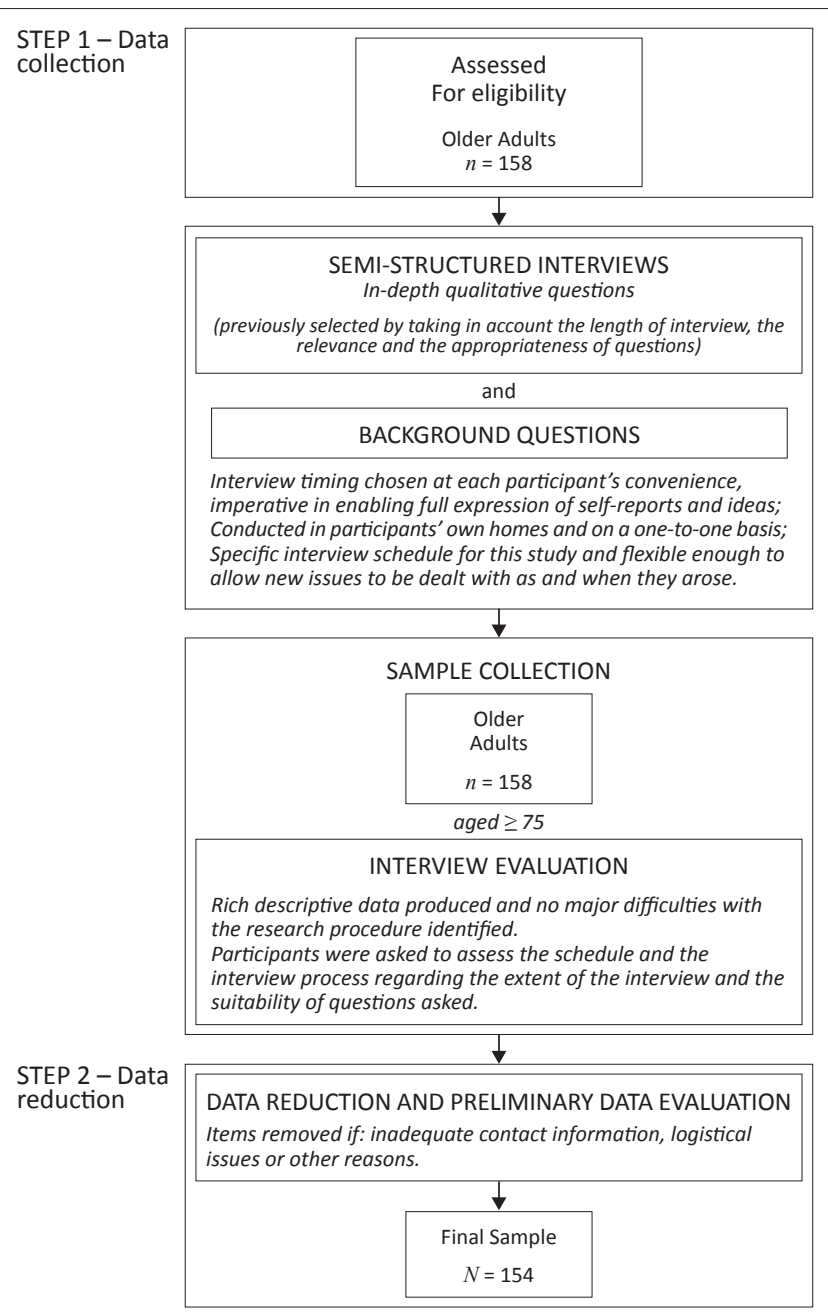

Source: Authors' own construction

FIGURE 2: Overview of the data-collection process.
During the interviews, the researcher assumed a neutral position in order to avoid bias in the investigation (Burns \& Grove 2005:55). Neutrality was kept by ensuring that the findings were a function solely of the participants and conditions of the research, with no researchers' interpretation. For this purpose, the researcher's own speculations, opinions, feelings, problems and prejudices were put aside during the interviews and when analysing the data. The interviews were conducted and audio-recorded by the researcher who had no previous relationship with any of the participants. Field notes were taken during and after each individual interview and were used to describe the interview dynamics and perspectives that emerged (Creswell 2003:189). Some of the participants asked to be apprised of the results at the end the study.

\section{Data analysis}

The first objective of this study was to explore older adults' SA and indicators of AtA. For this purpose, data were analysed by means of qualitative content analysis (Bardin 2007) and by using the following procedure: (a) definition of major emergent categories, mutually exclusive, for each one of the two pre-existing categories (SA and indicators of AtA); (b) creation of a list of coding cues; (c) analysis of verbatim quotes of participants' narratives in order to link them to emerging categories; (f) identification of subcategories, whilst preserving the principle of homogeneity of the category; (g) derivation of emergent categories, through constant comparison within and across interviews, allowing for the clustering of related subcategories until the point of theoretical saturation was reached (Bardin 2007:103; Fontanella, Ricas \& Turato 2008:17).

The approach to the analysis was based on an overarching concern for reflecting the participants' perspectives. To this end, the researchers decided on word sense as being the most appropriate unit of analysis as it would best reflect the participants' language usage and the style variations amongst the participants (e.g. the tendency of some participants to repeat ideas). The nominal variables were coded using an alpha-numeric code. The numerical code (one and two) distinguished between the SA and AtA indicators, respectively. The alphabetical code used the letters $\mathrm{A}$ to $\mathrm{F}$, being that each letter corresponded to one category (e.g. 'adapted' $=1 \mathrm{a}$; 'social networking' $=2 \mathrm{a}$ ). Additionally, a literature control ensured that there was a good fit between the reported data and pertinent literature. Our structure of subcategories and categories was then subjected to an external review and critical feedback was obtained from two reviewers with experience with older adults. Establishment of authority of the reviewer was ensured as follows: (a) the reviewer had to have obtained a Masters and a Doctoral degree in Health Psychology, equipping her or him with knowledge in health and wellbeing matters; (b) the reviewer had to have investigative skills and health care experience with older adults; and (c) the reviewer had to have developed experience in mixed research methods. An independent analysis of the 154 interviews was performed 
by a jury of two psychologists (both faculty) and a final group coresolution was made regarding the categories. After categorising the verbatim quotes of our participants, frequencies for each category were obtained by performing a word-frequency count.

The second objective of the study was to analyse the correlational structure of the pre-categories: SA, indicators of AtA and of a PAP overall model. For this purpose, coding of nominal categories to prepare them for MCA was completed; the associations between the emergent categories and latent constructs that can work as major determinants in older adults' conceptualisation of SA and indicators of AtA, by MCA were represented; and an analysis of the correlational structure of the pre-categories in our study was performed.

Statistical criteria included a minimum of $5.0 \%$ of the total variance explained by each dimension and a minimum eigenvalue of 1 for each dimension.

Data were analysed using the Statistical Package for Social Sciences for Windows (version 19.0; SPSS Inc., Chicago, IL) in the following manner. Firstly, frequency analysis was used to characterise the sample according to the sociodemographic and health-related characteristics. Secondly, because one of the objectives of the study was to explore older adults' SA and indicators of AtA, we performed a frequency analysis for the precategories (SA and indicators of AtA). Finally, because we aimed at analysing the correlational structure of SA, indicators of AtA and of a PAP overall model, we performed an MCA.

\section{Ethical considerations}

This study constitutes part of a multiphase project entitled, 'Older adults' adjustment to ageing and subjective wellbeing' for which ethical approval was given by the Research Unit in Psychology and Health at ISPA - Instituto Universitário [ethics approval reference number APROV/ET/05/2012]. Particular care was taken to observe all ethical requirements in view of the participants' age. Thus, the ethical principles of respect for autonomy, non-maleficence, beneficence and justice were adhered to throughout the research process (Dhai \& McQuoid-Mason 2011:43-44). Informed consent was received from all participants and the study protocol was approved by the Research Unit in Psychology and Health's coordination.

Privacy is an individual's right to determine the time, extent and general circumstances under which personal information will be shared or withheld from others (Burns \& Grove 2001:196), thus, participants' private information was not shared without the individual's knowledge or against their will. Also, at no time were participants identified and they were free to withdraw from the research at any time without penalty.

Participants' names were kept anonymous by using code names during interviews and filing of raw data. The selection process of participants was done fairly as each participant fitting the criteria had a chance of being selected. In-depth, individual interviews were conducted in the participants' homes. The participants, therefore, did not incur any financial expense (Burns \& Grove 2001:196; DENOSA [Democratic Nursing Organisation of South Africa] 1998:23). Benefits for participants included being given an opportunity to tell their perspectives in a positive, supportive environment in order to promote ageing well within old age.

\section{Trustworthiness}

Guba's model (Lincoln \& Guba 1985:216-217) for ensuring and assessing trustworthiness was employed in this study. The framework entails four main strategies for trustworthiness, namely credibility, transferability, dependability and neutrality. The credibility of the findings was ensured through:

- The accurate description of older adults' perspectives.

- Data verification with participants to ensure that data was adequately captured.

- The use of audio recordings to ensure that the researcher did not forget or misinterpret the participants' words and field notes to ensure that no significant observations would be forgotten.

- The use of in-depth interviews and the rapport established with participants in order to ensure an extended period of engagement.

- A field journal kept throughout the study, reflecting the daily schedule and the researcher's thoughts.

- The triangulation of data-collection methods by combining both qualitative and quantitative methods (e.g. semi-structured interviews, questionnaires) (Strauss \& Corbin 1990).

- A comparison of the findings with published studies and other literature (triangulation).

- The analysis and discussion of responses with a cocoder in order to ensure that the participants' true opinions were identified (triangulation).

- Consulting the study supervisor and colleagues to discuss the research process and findings.

- The use of semi-structured interviews and the informal conversational style in which they were conducted, allowing the participants to reflect freely on their perceptions.

- The researcher's experience of working with older populations and with qualitative data collection methods.

Transferability of the data was achieved through a detailed description of the participants' background information, the research context technique used to select participants and the analysis process (Graneheim \& Lundman 2004:109).

Dependability of the data was maintained through the adequate description of the research methods, code and recoding procedures of the data and methodology assessed by experts (Krefting 1991:125).

Finally, neutrality was ensured by the researcher's keeping the original interview schedule and the audio recordings, as well as the transcripts and notes, in order to provide an audit trail. 


\section{Results}

\section{Content analysis of the emergent categories}

Considering that the first objective of this investigation was to explore older adults' SA and indicators of AtA, results from the content analysis suggested five emergent categories for SA, namely, (a) 'adapted', (b) 'disconnected', (c) 'old', (d) 'youthful' and (e) 'tolerant' (see Table 2). These are in line with our conceptual framework in which SA is a multidimensional construct, assessing facets such as felt age and perceived age (Kotter-Grühn \& Hess 2012:563).

'Adapted' was the most-mentioned category for SA for the participants $(28.6 \%)$. This category was the most mentioned for all groups: Angolan 25.5\%, Romanian 34.7\% and English $25.7 \%$ (see Table 2).

These participants all stated that they felt adapted to their age and that their age corresponded with their expectations. Some of these statements can be seen in Table 3.

TABLE 2: Precategories and categories resulting from content analysis in Angolan, Romanian and English samples.

\begin{tabular}{|c|c|c|c|c|c|c|c|c|}
\hline \multirow[t]{2}{*}{ Variable } & \multicolumn{2}{|c|}{ Angolan } & \multicolumn{2}{|c|}{ Romanian } & \multicolumn{2}{|c|}{ English } & \multicolumn{2}{|c|}{ Total } \\
\hline & $N$ & $\%$ & $N$ & $\%$ & $N$ & $\%$ & $N$ & $\%$ \\
\hline \multicolumn{9}{|l|}{ Subjective age } \\
\hline Adapted & 56 & 25.5 & 78 & 34.7 & 62 & 25.7 & 196 & 28.6 \\
\hline Disconnected & 38 & 17.3 & 23 & 10.2 & 38 & 15.8 & 99 & 14.4 \\
\hline Old & 44 & 20.0 & 42 & 18.7 & 43 & 17.8 & 129 & 18.8 \\
\hline Youthful & 40 & 18.2 & 50 & 22.2 & 57 & 23.7 & 147 & 21.4 \\
\hline Tolerant & 42 & 19.0 & 32 & 14.2 & 41 & 17.0 & 115 & 16.8 \\
\hline $\begin{array}{l}\text { Score of precategory } \\
\text { 'subjective age' }\end{array}$ & 220 & 100.0 & 225 & 100.0 & 241 & 100.0 & 686 & 100.0 \\
\hline \multicolumn{9}{|c|}{ Indicators of adjustment to age (AtA) } \\
\hline Social networking & 53 & 14.6 & 52 & 12.4 & 65 & 15.6 & 170 & 14.2 \\
\hline Health & 56 & 15.5 & 49 & 11.7 & 79 & 18.9 & 184 & 15.3 \\
\hline Time perspective & 66 & 18.2 & 75 & 17.9 & 63 & 15.1 & 204 & 17.0 \\
\hline Spirituality & 68 & 18.8 & 80 & 19.1 & 70 & 16.7 & 218 & 18.2 \\
\hline Financial autonomy & 44 & 12.2 & 42 & 10.0 & 45 & 10.8 & 131 & 10.9 \\
\hline Professional activities & 41 & 11.3 & 74 & 17.7 & 57 & 13.6 & 172 & 14.3 \\
\hline Fulfilment and leisure & 34 & 9.4 & 47 & 11.2 & 39 & 9.3 & 120 & 10.1 \\
\hline Total & 362 & 100.0 & 419 & 100.0 & 418 & 100.0 & 1199 & 100.0 \\
\hline
\end{tabular}

Source: Authors' own construction

$N$, category frequency; $\%$, category percentage.
'Disconnected' was the least-mentioned category for SA for all groups: Angolan 17.3\%, Romanian 10.2\% and English $15.8 \%$ (see Table 2).

With regard to the indicators of AtA, the jury identified a total of seven categories, namely, (a) 'social networking', (b) 'health', (c) 'time perspective', (d) 'spirituality', (e) 'financial autonomy', (f) 'professional activities' and (g) 'fulfilment and leisure' (see Table 2).

'Spirituality' was the most-mentioned indicator of AtA amongst the participants (18.2\%), including Angolan (18.8\%) and Romanian (19.1\%) (see Table 2). These participants referred to the importance of spiritual beliefs for their adjustment to AtA. These participants also reported the proximity of death and the need to make the most of their time as being indicators of their AtA.

In comparison, English participants indicated 'health' as being a relevant indicator of AtA (e.g. physical wellbeing, absence of disease) (18.9\%) as contributing to their AtA (see Table 2):

'I go swimming every day. It's good for my body and for my

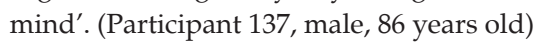

'Fulfilment and leisure' was the least-verbalised indicator of AtA by Angolan (9.4\%), and English (9.3\%) participants, whilst 'financial autonomy' was the least-reported indicator of AtA by Romanian participants (10.0\%) (see Table 2).

\section{Multiple correspondence analysis of the emergent categories}

The second aim of this investigation was to analyse the correlational structure of the precategories in our study: SA, indicators of AtA and of a PAP overall model and for this purpose, an MCA was performed.

Thus, the findings indicate the potential correlational structure and a model for each precategory and overall model, with diverse factors and factor loadings. SA is better explained by means of a two-dimensional model. The two factors, 'age-

TABLE 3: Sample participants' interview quotes.

\begin{tabular}{|c|c|c|c|}
\hline Category & Interview quote & Gender & Age (years) \\
\hline \multicolumn{4}{|l|}{ Subjective age } \\
\hline Adapted & 'I feel in peace with myself and with my age.' & Female & 78 \\
\hline Disconnected & 'I never think about my age. I'm too distant from that thought.' & Male & 76 \\
\hline Old & 'I feel I have lived a thousand years. The years have been a heavy load on me.' & Male & 79 \\
\hline Youthful & 'There is still a young heart beating inside of me.' & Female & 88 \\
\hline Tolerant & 'When we age, we cannot take everything seriously. We have to be benevolent towards our own age.' & Male & 78 \\
\hline \multicolumn{4}{|c|}{ Indicators of adjustment to age (AtA) } \\
\hline Social networking & 'I feel the need to be surrounded by the ones I love.' & Female & 75 \\
\hline Health & 'My body is still working very well.' & Male & 77 \\
\hline Time perspective & 'The clock is always there. I know I will not live forever so I want to make the most of it.' & Female & 79 \\
\hline Spirituality & 'I feel I have a purpose in life. Everything is interconnected in nature.' & Female & 77 \\
\hline Financial autonomy & 'I love the fact that I still have my own income.' & Female & 78 \\
\hline Professional activities & 'Nothing gives me more joy than drawing my sketches. That keeps me alive.' & Female & 93 \\
\hline Fulfilment and leisure & 'I'm always thinking on what I am going to do next in my house. I enjoy improving it.' & Male & 78 \\
\hline
\end{tabular}

Source: Authors' own construction 
conscientious' and 'young-at-heart', explained $89.8 \%$ of the total inertia (variance) observed (see Table 4).

As regards indicators of AtA, a three-dimensional model formed by 'reconciled', 'satisficers' and 'maximisers' was indicated by MCA as being a best-fit solution and explained $85.1 \%$ of the total inertia (see Table 5).

The results indicated a three-dimensional PAP overall model (accounting for $66.9 \%$ of the total variance) comprising 'agecognisant', 'fulfilled' and 'satisficers' (see Table 6).

TABLE 4: Two-dimensional representation for 'subjective age': Factor loadings for each dimension, mean loadings and percentage inertia (variance) explained.

\begin{tabular}{lccc}
\hline Categories & \multicolumn{3}{c}{ Dimensions } \\
\cline { 2 - 4 } & Age conscientious & Youthful & Mean \\
\hline Adapted & $\mathbf{0 . 7 4 2}$ & 0.170 & 0.456 \\
Disconnected & 0.487 & $\mathbf{0 . 4 9 6}$ & 0.491 \\
Old & $\mathbf{0 . 7 4 5}$ & 0.109 & 0.427 \\
Youthful & 0.487 & $\mathbf{0 . 4 9 6}$ & 0.491 \\
Tolerant & 0.216 & $\mathbf{0 . 5 4 2}$ & 0.379 \\
Eigenvalue & 2.676 & 1.812 & 2.244 \\
Total inertia & 0.535 & 0.362 & 0.448 \\
\% of variance & 53.517 & 36.242 & 44.880 \\
\hline
\end{tabular}

Source: Authors' own construction

TABLE 5: Three-dimensional representation for 'indicators of AtA': Factor loadings for each dimension, mean loadings and percentage inertia (variance) explained.

\begin{tabular}{lcccc}
\hline Categories & \multicolumn{4}{c}{ Dimensions } \\
\cline { 2 - 5 } & Reconciled & Satisficers & Maximisers & Mean \\
\hline Social networking & 0.011 & $\mathbf{0 . 7 5 5}$ & 0.000 & 0.255 \\
Health & 0.002 & $\mathbf{0 . 6 7 6}$ & 0.044 & 0.241 \\
Time perspective & $\mathbf{0 . 7 5 2}$ & 0.000 & 0.192 & 0.315 \\
Spirituality & $\mathbf{0 . 6 6 4}$ & 0.023 & 0.220 & 0.302 \\
Financial autonomy & 0.195 & $\mathbf{0 . 5 0 8}$ & 0.072 & 0.258 \\
Professional activities & 0.297 & 0.001 & $\mathbf{0 . 6 1 0}$ & 0.303 \\
Fulfilment and leisure & 0.421 & 0.003 & $\mathbf{0 . 5 1 0}$ & 0.311 \\
Eigenvalue & 2.342 & 1.966 & 1.649 & 1.985 \\
Total inertia & 0.335 & 0.281 & 0.236 & 0.284 \\
\% of variance & 33.452 & 28.087 & 23.553 & 28.364 \\
\hline
\end{tabular}

Source: Authors' own construction

TABLE 6: Three-dimensional representation for an overall model age 'personal age perceptions': Factor loadings for each dimension, mean loadings and percentage inertia (variance) explained.

\begin{tabular}{lcccc}
\hline Categories & \multicolumn{4}{c}{ Dimensions } \\
\cline { 2 - 5 } & Age-cognisant & Fulfilled & Satisficers & Mean \\
\hline Adapted & $\mathbf{0 . 5 8 0}$ & 0.085 & 0.002 & 0.222 \\
Disconnected & $\mathbf{0 . 5 4 7}$ & 0.115 & 0.022 & 0.228 \\
Old & $\mathbf{0 . 6 1 9}$ & 0.018 & 0.001 & 0.212 \\
Youthful & $\mathbf{0 . 5 4 7}$ & 0.115 & 0.022 & 0.228 \\
Tolerant & 0.071 & $\mathbf{0 . 2 9 8}$ & 0.101 & 0.157 \\
Social networking & 0.049 & 0.001 & $\mathbf{0 . 6 2 7}$ & 0.225 \\
Health & 0.146 & 0.064 & $\mathbf{0 . 5 3 5}$ & 0.248 \\
Time perspective & 0.226 & $\mathbf{0 . 4 9 1}$ & 0.000 & 0.239 \\
Spirituality & $\mathbf{0 . 3 4 4}$ & $\mathbf{0 . 3 3 4}$ & 0.007 & 0.228 \\
Financial autonomy & 0.010 & 0.185 & $\mathbf{0 . 4 0 7}$ & 0.201 \\
Professional activities & 0.195 & $\mathbf{0 . 3 0 2}$ & 0.157 & 0.218 \\
Fulfilment and leisure & 0.122 & $\mathbf{0 . 5 3 4}$ & 0.148 & 0.268 \\
Eigenvalue & 3.457 & 2.540 & 2.031 & 2.676 \\
Total inertia & 0.288 & 0.212 & 0.169 & 0.223 \\
\% of variance & 28.806 & 21.163 & 16.921 & 22.297 \\
\hline SOurce Authors & & & &
\end{tabular}

Source: Authors' own construction

\section{Discussion}

This investigation was centered around two main research questions: (1) How do older adults perceive SA and AtA?; and (2) What is the pattern of relationships of SA, indicators of AtA and of the PAP model?

The participants of our study expressed a positive perceived age $(66.8 \%$ of overall narratives). 'Adapted' was the mostreferred-to SA for older adults. As suggested by previous studies, success in fulfilling challenges may yield more positive perceived age (Kleinspehn-Ammerlahn, KotterGrühn \& Smith 2008:384; Ward 2010). Additionally, this study indicated the emergence of objective (e.g. health) and subjective categories (e.g. time perspective) as indicators of AtA, within the interrelated context of ageing well. 'Spirituality' and 'time perspective' were the most frequent indicators of AtA pointed out by the participants of this study. These results corroborated existing literature (Malette \& Oliver 2006:31; Mowat 2004).

Growing literature emphasises self-perception of age as a personal evaluation of one's own age and that cultural, national and ethnical differences may influence the process of ageing (Barak 2009; Kotter-Grühn \& Hess 2012; Löckenhoff et al. 2009; Montepare 2009; Torres 2003; Ward 2010). As expected, our results indicated a diversity of older adults' perspectives concerning age and adjustment amongst the three nationalities. In detail, 'adapted' was the most referred SA by our participants. This was valid for the Angolan (25.5\%), Romanian (34.7\%) and English (25.7\%) participants, whilst 'spirituality' was the most-mentioned indicator of AtA by the participants (18.2\%), including Angolans (18.8\%) and Romanians (19.1\%). In contrast, the English participants indicated 'health' as being the most frequent indicator of AtA (18.9\%)

A potential correlational structure indicates a model for each of the cited pre-categories and for a PAP overall model. MCA indicates that SA can be explained by two factors: 'age conscientious' is represented by 'adapted' and 'old', given the strong relation with feeling adapted and feeling old. Previous literature highlights the fact that SA derives from a process of anchoring and adjusting personal age perceptions, considering distal cues and proximal reference points that guide the age that individuals across the lifespan perceive themselves to be (Montepare 2009:42).

The second factor, 'youthful', is embodied by 'disconnected', 'youthful' and 'tolerant'; therefore, these older adults feel detached, relaxed and youthful about their age. In fact, with age, older adults reported increasingly-younger subjective ages. These results are in line with the pivotal study of Kastenbaum et al. (1972). Previous studies indicate that 'feeling younger' was rated more positively by older adults than younger adults (Giles et al. 2010). Moreover, older adults reported that they felt conscientious and more agreeable than middle-aged and younger adults (Allemand, Zimprich \& Hendriks 2008). Therefore, it stands to reason that these older adults might feel conscientious or youthful about their age. 
Indicators of AtA are elucidated by three major factors: (a) 'reconciled' is embodied by 'time perspective' and 'spirituality'; therefore these older adults reflect and balance time, age, sense of limit and other spiritual issues; (b) 'satisficers' is composed by 'social networking', 'health' and 'financial autonomy'; thus older adults invest in family, health and autonomy; and (c) 'maximisers' is represented by 'professional activities' and 'fulfilment and leisure'; therefore these older adults want to invest in personal projects and maximise their decisions, given the strong relation between fulfilment, leisure and profession. Literature suggests that, although there is little research about older adults' decision making (Parks \& Schwarz 1999), age-related, experience and culture demands have been highlighted with regard to decision making by older populations (Mather 2006). Conversely, maximising was related negatively to life satisfaction, self-esteem, optimism and happiness (Parker, de Bruin \& Fischhoff 2007:348; Tanius et al. 2009:94). It is of note, however, that some authors found no relationship between the maximising tendency and life satisfaction (Diab, Gillespie \& Highhouse 2008:368). Furthermore, in Tanius and colleagues' study (2009:94), older adults were more likely to be characterised as satisficers. Moreover, previous studies indicate that older individuals search for existential meaning and conscious ageing (Malette \& Oliver 2006:31; Wong 2000).

The MCA regarding the correlational structure of the two cited precategories, emphasises that these are explained by a three-factor PAP overall model. Thus, the first factor ('age cognisant') consisted of 'adapted', 'disconnected', 'old' and 'youthful'; the second factor ('fulfilled') was formed by 'time perspective' and 'fulfilment and leisure'; and the third factor ('satisficers') comprised 'social networking' and 'health'. The remaining categories had a low loading $(<0.450)$ in the three factors, which indicated that these categories are not very significant in connection with these factors. Furthermore, results indicate that in the PAP overall model, the factor 'age cognisant' specifies categories in common with the factors 'age conscientious' and 'youthful' from the SA model; that the factor 'fulfilled' indicates categories in common with the factor 'reconciled' and 'maximisers' from the 'indicators of AtA' model; and that the factor 'satisficers' includes categories that are also part of the factor 'satisficers' from the 'indicators of AtA' model, corroborating previous studies that older adults were more likely to be characterised as satisficers (Tanius et al. 2009). Moreover, literature highlights productive activities (Wahrendorf \& Siegrist 2010:67) as contributing to the wellbeing of older adults, as well as the importance of age identities and age awareness (Barak 2009; Diehl \& Wahl 2010:340; Schafer \& Shippee 2010) as key factors for personal perception of age.

\section{Limitations and implications of the study}

Although a diverse sample of participants was recruited, the use of a purposeful sampling method could have resulted in some selection bias. As in other qualitative studies, there is no certainty that different researchers would not come up with different categories and subcategories. Yet, qualitative research was necessary in order to maximise validity and to highlight the need for researchers and health professionals to be perceptive to the varying needs of older adults. Additionally, the interviews were only semi-structured. Even though the interviews were conducted with a view to being free of bias, two core areas were predefined as needing to be addressed. Interviews thus tended to be steered toward these areas, which could have biased the results. Moreover, our findings cannot be generalised to other samples and only reveals the perceptions of our participants. The current research merely scratched the surface of a very pertinent study field and it indicated only relevant clues to take into account in broad assessment for older adults, service planning and future research. Although this sample comprised older adults from 75 to 99 years old, more studies are needed with older adults younger than 75 . Furthermore, the impact of variables such as social support, health status and education of the participants were not explored in the current study and could be studied in future investigations. Predictive relationships should also be considered in future research. The deepening from these investigations would provide the knowledge to address AtA and SA in old age more effectively. Finally, additional research is needed into the conceptual framework of AtA and SA for older adults.

\section{Conclusion}

This research aimed to investigate the conceptualisation of SA and AtA by means of semi-structured interviews and to analyse the correlational structure of the pre-categories in our study: SA, indicators of AtA and of a PAP overall model. Instead of being measured based only on quantitative measures (e.g. self-report questionnaires), we assert that the results of this study are an original contribution for a better understanding of what actually constitutes older adults' perceptions of age and ageing. Taken together, our results lend further support to the usefulness of older adults' selfreports to deepening the distinctiveness of their experiences concerning the multidimensional and cross-cultural context of age and the ageing process.

Because a more accurate match should exist between what public health and social service professionals have in mind for older adults and their own self-reports, the practical implications of this study may represent the groundwork for changes in the community services, which can address prevention services as well as services for existing conditions, such as centres for prevention to address wellbeing and healthcare in old age. Moreover, the implication for the clinical and social professionals is to invite older adults for an open discussion of age and ageing matters, as appropriate. These may help with ageing challenges by preventing health problems, increasing congruence between chronological age and perceived age, promoting social integration and ageing well. The evidence of variety regarding ageing well presented in this paper is an important contribution to the underdeveloped potential of the AtA concept in this population and its association with SA, in an overall model of personal perception of age. 
Growing evidence in gerontology and geriatrics is demonstrating that the potential of older people for ageing well in different cultures is relatively unexplored, thus this study's outcome could be useful in clinical practice, service planning and evaluation with cross-national older populations. In fact, because the ageing of the population is becoming a pressing reality for both African and European countries, gerontologists need to expand their horizons of interest to include a multidimensional and multicultural approach. In brief, we consider that by exploring SA and AtA in greater depth, gerontologists will at least be better able to enlighten the pertinence of ageing well.

\section{Acknowledgements}

The authors kindly acknowledge the Portuguese Foundation for Science and Technology (FCT) for funding received which assisted in the realisation of this research [grant number SFRH/BD/44544/2008].

\section{Competing interests}

The authors declare that they have no financial or personal relationship(s) which may have inappropriately influenced them in writing this article.

\section{Authors' contributions}

S.v.H. (Research Unit in Psychology and Health, ISPA) was responsible for the study concept and design, analysis and interpretation of data and elaboration of the manuscript. I.L. and F.P. (Research Unit in Psychology and Health, ISPA) made conceptual contributions and reviewed the manuscript. G.N. (Romanian Association of Person-Centered Psychotherapy) performed data collection and made conceptual contributions. All authors read and approved the final manuscript.

\section{References}

Allemand, M., Zimprich, D. \& Hendriks, A.A.J., 2008, 'Age differences in five personality domains across the life span', Developmental Psychology 44(3), 758-770. http:// dx.doi.org/10.1037/0012-1649.44.3.758, PMid:18473642

Barak, B., 2009, 'Age identity: A cross-cultural global approach', International Journal of Behavioral Development 33, 2-11. http://dx.doi.org/10.1177/0165025408099485

Bardin, L., 2007, Análise de conteúdo [Content analysis], Edições 70, Lisbo

Birren, J.E. \& Schaie, K.W., 1996, Handbook of the psychology of aging, Academic Press, San Diego.

Brandstädter, J. \& Greve, W., 1994, 'The aging self: stabilizing and protective processes', Developmental Review 14(1), 52-80. http://dx.doi.org/10.1006/drev.1994.1003

Brink, H., 2006, Fundamentals of research methodology for health care professionals, 2nd edn., Juta, Cape Town.

Burns, N. \& Grove, S.K., 2001, The practice of nursing research: Conduct, critique and utilization, W.B. Saunders, Philadelphia.

Burns, N. \& Grove, S.K., 2005, The practice of nursing research, 5th edn., Saunders, Philadelphia.

Charlton, K., 1998, 'Health, health care and ageing in Africa: challenges and opportunities', Southern African Journal of Gerontology 7(2), 1-3.

Creswell, J.W., 2003, Research design. Qualitative, quantitative and mixed methods approaches, Sage Publications, California.

DENOSA (Democratic Nursing Organisation of South Africa), 1998, Ethical standards for nurse researchers, DENOSA, Pretoria

Dhai, A. \& McQuoid-Mason, D., 2011, Bioethics, Human Rights and Health Law: Principles and Practice, Juta \& Company Ltd, Cape Town.

Diab, D.L., Gillespie, M.A. \& Highhouse, S., 2008, 'Are maximizers really unhappy? The measurement of maximizing tendency', Judgment and Decision Making 3(5), 364-370.
Diehl, M.K. \& Wahl, H.W., 2010, 'Awareness of age-related change: Examination of a (mostly) unexplored concept', The Journals of Gerontology, Series B: Psychological Sciences and Social Sciences 65B(3), 340-350. http://dx.doi.org/10.1093/geronb/ Sciences and Social Sciences 65B(3), 340-350
gbp110, PMid:20008026, PMCid:2853600

Fernández-Ballesteros, R., 2007, GeroPsychology. European Perspectives for and Ageing World, Hogrefe \& Huber, Gottingen.

Ferreira, M., Møller, V., Prinsloo, F. \& Gillis, L.S., 1992, Multidimensional survey of elderly South Africans, 1990/91: key findings, HSRC/UCT Centre for Gerontology, Cape Town.

Folstein, M.F., Folstein, S.E. \& McHugh, P.R., 1975, "'Mini-mental state". A practical method for grading the cognitive state of patients for the clinician', Journal of Psychiatric Research 12(3), 189-198. http://dx.doi.org/10.1016/0022-3956(75)90026-6

Fontanella, B.J.B., Ricas, J. \& Turato, E.R., 2008, 'Amostragem por saturação em pesquisas qualitativas em saúde: contribuições teóricas' [Saturation sampling in qualitative health research: theoretical contributions], Cadernos de Saúde Pública 24(1),
http://dx.doi.org/10.1590/S0102-311X2008000100003, PMid:18209831

Giles, H., Mcllrath, M., Mulac, A. \& McCann, R.M., 2010, 'Expressing age salience: three generations' reported events, frequencies, and valences', International Journal of the Sociology of Language, 206, 73-96.

Graneheim, U.H. \& Lundman, B., 2004, 'Qualitative content analysis in nursing research: concepts, procedures and measures to achieve trustworthiness', Nurse Education Today 24(2), 105-112. http://dx.doi.org/10.1016/j.nedt.2003.10.001

Holloway, I. \& Wheeler, S., 2002, Qualitative research for nurses, Blackwell Science, Australia.

Kastenbaum, R., Derbin, V., Sabatini, P. \& Artt, S., 1972, "'The ages of me": Toward personal and interpersonal definitions of functional aging', The International Journal personal and interpersonal definitions of functional aging, The International Journal
of Aging and Human Development 3(2), 197-211. http://dx.doi.org/10.2190/TUJRof Aging and Human
WTXK-866Q-8QU7

Kleinspehn-Ammerlahn, A., Kotter-Grühn, D., \& Smith, J., 2008, 'Self-perceptions of aging: Do subjective age and satisfaction with aging change during old age?', The Journals of Gerontology, Series B: Psychological Sciences and Social Sciences 63B(6), 377-385. http://dx.doi.org/10.1093/geronb/63.6.P377

Kotter-Grühn, D. \& Hess, T., 2012, 'The impact of age stereotypes on self-perceptions of aging across the adult lifespan', Journal of Gerontology, Series B: Psychological Sciences and Social Sciences 67(5), 563-571. http://dx.doi.org/10.1093/geronb/ gbr153

Kozma, A., Stones, M.J. \& McNeil, J.K., 1991, Psychological well-being in later life, Butterworths, Markham.

Krefting, L., 1991, 'Rigor in qualitative research: the assessment of trustworthiness' The American Journal of Occupational Therapy 45(3), 214-222. http://dx.doi.org/ The American Journal of
10.5014/ajot.45.3.214

Levy, B.R., 2003, 'Mind matters: Cognitive and physical effects of aging self-stereotypes', Journal of Gerontology, Series B: Psychological Sciences and Social Sciences 58B(4), 203-211. http://dx.doi.org/10.1093/geronb/58.4.P203

Lincoln, Y. \& Guba, E., 1985, Naturalistic inquiry, Sage, London. http://dx.doi.org/10.1016/ 0147-1767(85)90062-8

Löckenhoff, C.E., De Fruyt, F., Terracciano, A., McCrae, R.R., De Bolle, M. \& Costa, P.T. Jr. et al., 2009, 'Perceptions of aging across 26 cultures and their culture-level associates', Psychology and Aging 24(4), 941-954. http://dx.doi.org/10.1037/a0016901

Malette J. \& Oliver, L., 2006, 'Retirement and existential meaning in the older adult: A qualitative study using life review', Counselling, Psychotherapy and Health 2(1), A qualit.

Mather, M., 2006, 'A review of decision-making processes: Weighing the risks and benefits of aging', in L.L. Carstensen \& C.R. Hartel (eds.), When I'm 64, pp. 145-173, The National Academies Press, Washington.

Montepare, J.M., 2009, 'Subjective age: Toward a guiding lifespan framework', International Journal of Behavioral Development 33(1), 42-46. http://dx.doi. org/10.1177/0165025408095551

Mowat, H., 2004, 'Successful ageing and the spiritual journey', in A. Jewel (eds.), Ageing, spirituality and well-being, pp. 42-57, Jessica Kingsley, London.

Parker, A.M., de Bruin, W.B., \& Fischhoff, B., 2007, 'Maximizers versus satisficers: Decision-making styles, competence, and outcomes', Judgment and Decision Making Decision-making
2(6), 342-350.

Parks, D.C. \& Schwarz, N., 1999, Cognitive aging: A primer, Routledge, New York.

Polit, D.F. \& Hungler, B.P.P., 2004, Nursing research: Principles and methods, JB Lippincot, Philadelphia.

Schafer, M.H., \& Shippee, T.P., 2010, 'Age identity in context: Stress and the subjective side of aging', Social Psychology Quarterly 73(3), 245-264. http://dx.doi.org/ 10.1177/0190272510379751

Slangen-de Kort, Y.A., Midden, C.J., Aarts, H. \& Wagenberg, F., 2001, 'Determinants of adaptive behavior among older persons: self-efficacy, importance, and personal disposition as directive mechanisms', International Journal of Aging and Human disposition as directive mechanisms', International Journal of Aging and Human
Development 53(4), 253-274. http://dx.doi.org/10.2190/V52N-Q5VN-C3KW-0LY9, Development $53(4)$
PMid:11890169

Staudinger, U.M. \& Kunzmann, U., 2005, 'Positive adult personality development: adjustment and/or growth?', European Psychologist 10(4), 320-329. http://dx.doi. org/10.1027/1016-9040.10.4.320

Steverink, N., Westerhof, G.J., Bode, C. \& Dittmann-Kohli, F., 2001, 'The personal experience of aging, individual resources, and subjective wellbeing', The Journals of Gerontology, Series B: Psychological Sciences and Social Sciences 56B(6), 364-373. $\mathrm{http}: / / \mathrm{dx}$.doi.org/10.1093/geronb/56.6.P364

Strauss, A. \& Corbin, J., 1990, Basics of qualitative research: Grounded theory procedures and techniques, Sage Publications, Newbury.

Tanius, B.E., Wood, S., Hanoch, Y. \& Rice, T., 2009, 'Aging and choice: Applications to Medicare Part D', Judgment and Decision Making 4(1), 92-101. 
Torres, S., 2003, 'A preliminary empirical test of a culturally-relevant theoretical framework for the study of successful aging', Journal of Cross-Cultural Gerontology
18(1), 79-100. http://dx.doi.org/10.1023/A:1024830629385, PMid:14617959

United Nations, 2009, World Population Prospects: The 2008 Revision, CD-ROM Edition - Extended Dataset, United Nations.

Wahrendorf, M., \& Siegrist, J., 2010, 'Are changes in productive activities of older people associated with changes in their well-being? Results of a longitudina European study', European Journal of Ageing 7(2), 59-68. http://dx.doi.org/10.1007/ s10433-010-0154-4

Ward, R.A., 2010, 'How old am I? Perceived age in middle and later life', The International Journal of Aging and Human Development 71(3), 167-184. http:// dx.doi.org/10.2190/AG.71.3.a
Westerhof, G.J., Whitbourne, S.K. \& Freeman, G.P., 2011, 'The aging self in a cultural context: The relation of conceptions of aging to identity processes and selfesteem in the United States and the Netherlands', Journal of Gerontology, Series B: Psychological Sciences and Social Sciences 67B(1), 52-60. http://dx.doi.org/

Whitbourne, S.K., 1986, Adult development, Praeger, New York.

Wong, P.T.P., 2000, 'Meaning in life and meaning in death in successful aging', in A. Tomer (eds.), Death attitudes and the older adult, pp. 23-36, Brunner/Mazel Publisher, New York. PMid:10914390

World Health Organization, 2003, Directory of Research on Ageing in Africa: 19952003, WHO, Geneva, Switzerland. 